\title{
How can we envision smallholder positioning in African agribusiness? Harnessing innovation and capabilities
}

\author{
Nafiisa Sobratee \\ Shamim Bodhanya \\ University of KwaZulu Natal, Durban, South Africa
}

\section{Keywords}

Social entrepreneurship, agribusiness, developing countries, complexity science, leadership capabilities, transformation, agricultural innovation platforms

\begin{abstract}
The intricate nature of the African agricultural-food system and the related multi-sectoral value chains capability challenges means that efforts to transform the current landscape to achieve food security in developing countries cannot escape complexity. A burgeoning body of research that uses the innovation systems approach to drive agricultural development in developing countries is emerging. In this article, we argue that social agro-entrepreneurship has the potential to create the possibility space to make smallholder ventures sustainable.

This can be achieved via collective approach to transformation provided within agricultural innovation platforms. The development of agribusiness capabilities is considered from the complexity science perspective. We draw an analogy from the theoretical framework provided by the Leadership Capabilities Model of Hazy (2006) to explain how strategic institutional entrepreneurship can co-evolve towards fit within innovation platforms by harnessing capabilities simultaneously across sectors and at different levels through adaptive governance. Cross-sector partnerships are important to leverage the transformation of the smallholder sector towards stable ventures.
\end{abstract}

Corresponding author: Nafiisa Sobratee

Email address for corresponding author: nsobratee@yahoo.com

First submission received: 9th March 2017

Revised submission received: 20th April 2017

Accepted: 19th July 2017

\section{Acknowledgement}

The authors would like to thank the University of KwaZulu Natal for funding this publication.

\section{Introduction}

There is a large body of work debating on the food security problematique (Fuss et al., 2015; Godfray et al., 2010; Slimane, Huchet-Bourdon \& Zitouna et al., 2015). Yet, challenges remain. The potential for agribusiness development to harness smallholder agricultural development has been suggested as an option for reducing hunger and enhancing overall economic growth in developing countries (Banson et al., 2015, HLPE, 2013; World Bank, 2013).What role can agribusiness development play in ensuring food security among smallholders in the developing world?

Sub-Saharan Africa is home to most of the world's agriculture-based countries (AGRA, 2014; Banson et al., 2015). Despite increased attention to and financing for African agriculture over the last decade, the expected research impacts remain obscure and the potential of the smallholder sector remains largely untapped (Babu, Manvatkar \& Kolavalli et al., 2015). Smallholders represent the overwhelming majority of all farms in Africa and produce up to $90 \%$ of the food in some countries. But they need better connections to market and more cooperation amongst each other as collectives (Bolo, 2016). The sector is plagued by many constraints, such as poorly functioning farmer organisation, limited access to markets, inadequate agricultural financing, failure of the land tenure system, inadequate electricity supply, absence of irrigation systems, poor communication 
infrastructure and road networks (Sheahan and \& Barrett, 2014). These problems are compounded by concatenated issues, such as political instability, climate change, trade globalisation, unstable commodity prices, rising energy costs, new waves of technologies which remain out of reach, amongst other issues (Chauvin, Mulangu \& Porto et al., 2012; Fuglie and \& Rada, 2013).

In the following section, we describe how the approach to agricultural rural development has shifted from the traditional linear model of technology diffusion and adoption to that of creating whole systems change through Innovation Platforms. This concept is one of the latest 'tools' that fall within agricultural innovation systems application which has been applied among some smallholder communities to improve the performance of agricultural rural transformation in some parts of Africa (Roling, 2016; Van Paassen et al., 2014). Sustainable agribusiness and rural enterprise development therefore, has been identified as one of the pathways that can make smallholders successful on the long-term in improving their farm ventures and eventually their food security status. Challenges remain (Khanna and \& Palepu, 2013; Raikundalia, 2016). In this paper, we draw on the concept of social entrepreneurship's potential to improve our understanding about the ways in which smallholders' capabilities can be unleashed to enable them to upgrade to sustainable ventures. Thus, we propose the mainstreaming of the social entrepreneurship within agricultural Innovation Platforms (IP) in developing countries in order to trigger the development of smallholder farming and agribusinesses. The Leadership Capabilities Model of Hazy (2006) is used to illustrate how metacapabilities can be harnessed to enable this.

\section{Agribusiness developments in the context of social entrepreneurship \\ 2.1 What is social entrepreneurship?}

A social business is an enterprise that has a dual bottom line of financial stability and social profit (Schultz, 2009). This corresponds closely to Muhammad Yunus's, Nobel Prize Winner 2009 and founder of the Grameen Bank, interpretation that a social business is a subset of the idea of social entrepreneurship. It relates to an enterprise that uses free market principles to address a pressing social problem - such as poverty or homelessness. In the development of her social entrepreneurship Matrix, Masetti (2009) explained that social businesses must be profitable and sustainable, but instead, profit is shared with the investors and the organisation/business. This requires a shift from the traditional bottom line accounting to the so-called triple bottom-line accounting, which considers economic, environmental and social benefits. According to Peredo and \& McLean (2006), social entrepreneurship is defined as a state of the social system:

"Social entrepreneurship is exercised where some person or persons aim either exclusively or in some prominent way to create social value of some kind and pursue that goal through some combination of

- recognising and exploiting opportunities to create this value

- employing innovation

- tolerating risk and

- brushing aside limitations and available resources" (p.13).

We use this definition because it can reflect the dynamic and continuously emerging social patterns of agents and collective actions, which can be both constructive and destructive, which that is required to embed agribusiness and rural enterprise within agricultural innovation platforms aiming at improving food security in Africa. This is also in line with the notion that agricultural innovation platforms are complex adaptive systems with the potential for organisational capabilities that can be unleashed though leadership.

\subsection{In what capacities does social agribusiness leverage smallholders' ability to contribute to national food security?}

Smallholders contribute to world food security and nutrition while performing other related roles in their territories. Historical evidence shows that smallholder agriculture, adequately supported by policy and public investments, has the capacity to contribute effectively to food 
security and food sovereignty (HLPE, 2013). Within an enabling political and institutional environment, it can also substantially lead to economic growth, the generation of employment, poverty reduction, the emancipation of neglected and marginalised groups, and the reduction of spatial and socio-economic inequalities.

What type of investment sources sustains the smallholder sector in developing African countries? Public investments in and for agriculture have fallen considerably since the 1980s. It is now widely recognised that agriculture has been neglected at both the national and international levels. Many agricultural banks have discontinued their commercial transactions, and extension services, applied research and investment in infrastructure projects have declined since the mid1980s (Pingali et al., 2012). Most investments in smallholder agriculture are realised by smallholders themselves. This occurs through different modalities but mostly through labour investments to enlarge and improve the resource base, and to a lesser extent through personal savings and remittances from family members that are used for the acquisition of additional resources (Swaminathan, 2010). However, these investments are limited since domestic needs receive priority when food, health or education expenditures are at risk.

In Africa, 80 percent of the holdings are below 2 ha. Even then, the potential efficiency of smallholder farming relative to larger farms have been widely documented, focusing on the capacity of smallholders to achieve high production levels per unit of land through the use of family labour or other types of collectives in diversified production systems (Graeub et al., 2016; Swaminathan, 2010; Tittonell et al., 2010). Major corporations and other private sector companies were expected to provide the appropriate market services as well as the technical knowledge to help producers upgrade their standards in order to meet market requirements. This has occurred in some places, but not in most, and often not in ways that have benefited smallholders (Bolo, 2016). When related to the total number of smallholders, only a minority has actually been able to participate in such schemes.

\subsection{Agricultural Innovation Systems}

Research interventions in agricultural development have predominantly focused on the traditional linear model of technology diffusion and uptake to improve livelihood. While Asia experienced a rapid increase in food production and yields during the Green Revolution in the late 1970s and early 1980s, in Sub-Saharan Africa (SSA) per capita food production and yields have stagnated (Pingali, 2012; Roling, 2016). In SSAub-Saharan Africa, this approach to Agriculture Innovation Systems (AIS) has been unsuccessful. Roling (2016) referred to this failed approach as the Business Model of Agriculture (BMA). This pathway to achieve agricultural innovation development among smallholders in developing countries is based on deriving high internal rate of return from investment in technology. "An innovation system is a network of organiszations, enterprises, and individuals focused on bringing new products, new processes, and new forms of organiszation into economic use, together with the institutions and policies that affect their behavior and performance." (World Bank, 2013, p.2). The failure of agriculture to take off in SSA within such a pathway has been attributed to the lack of supportive policy environment to counteract the dependence on rainfed agriculture; low population densities; the lack of infrastructure, markets, and supporting institutions; the agro-ecological complexities and heterogeneity of the region; low use of technologies and inputs (Moyo, Bah \& Verdier-Chouhane et al., 2015; Mytelka, 2016; World Bank, 2008).

Unfortunately, this approach stems from the adoption of a reductionist understanding of how science informs policy and practice (Leach, 2008) for it neither admits multiple partial perspectives nor the idea that praxis, theory-informed practical action, is contextual and dynamic. According to (Ison, (2010). Thus, accelerated agricultural growth is broadly transformative. This transformation can be realised by catalysing an entrepreneurial environment that starts on the farm (HLPE, 2013). Rising agricultural productivity can encourage broad entrepreneurial activities such as diversification into new products, the growth of rural service sectors, emergence of agroprocessing industries, and expansion into new markets (Diao, Headey \& Johnson et al., 2008). 
Adopting a sustained approach to growing farm incomes raises the demand for industrial goods, lowers food prices, and curbs inflation.

In order to stir such large-scale transformation, policy makers and development actors have been focusing on the setting up of Innovation Platforms (IP) (Francis, 2016). It entails fundamental shifts in how the agricultural sector utilises and implements innovative technology to improve output in a sustainable manner and address the need for greater food security in the developing world. A growing body of knowledge is emerging to understand how these shifts, mainly via largescale systemic change, within smallholder agriculture communities can leverage sustainable farming and rural enterprise ventures. IP involves transformative change (Ison, Blackmore \& Iaquinto et al., 2013). In this model of AIS, practitioners need to understand the relational dynamics at play within interventions to create opportunities for the convergence of enabling conditions and improve governance mechanisms (Roling, 2016). This involves the process of social learning whereby institutional complexity has to be appreciated and made apparent to improve the understanding of the systemic implications that enable governance. How do we need to appreciate the governance processes that nurture the transformation of agricultural system innovation in developing countries?

\section{Agro-entrepreneurship within Innovation Platforms}

In this paper, the strategic focus is to demonstrate that smallholders' sustainability can be leveraged via entrepreneurship development. An analysis of how change is already taking place via STI, seen within the perspective of the drivers that lead to the transformation, will improve our understanding of how in order to boost smallholder productivity, there is a need to develop crosssector agribusiness and rural enterprise. For instance, the inexistence of an established distributed irrigation system in SSA is one of the major constraints to ensure that farmers' investment in cropping practices end up in producing a yield. We take the example of how when farmers, in Kenya, are provided with the option of using mobile money, they are able to acquire the "pata pump', from a social entrepreneurship scheme, to irrigate their plots, improve yield and sell their produce (Box 1).

Box 1. Harnessing capabilities to ensure on-farm productivity by improving access to distributed irrigation systems

Improving access to distributed irrigation systems through mobile finance in Kenya
In a comprehensive study on the potential that irrigation can have in driving agricultural
development in Sub-Saharan Africa, Burney, Naylor \& Poste et al. (2013) explicate how distributed
irrigation systems should be prioritised to improve productivity. Although irrigation schemes have
been promoted in the sub-Saharan region, the impact has not been as expected (Faures \& and
Santini, 2008). Yet, Hussain \&and Hanjra (2004) had identified three main inter-linked impact
pathways through which irrigation can help the agricultural sector to play its role as an engine of
growth and poverty reduction. Within the micro-pathway, it increases returns to physical, human,
and social capital of poor households. At the meso-pathway, market participation opportunities are
improved by integrating the poor into factor-product and knowledge/information markets. This
includes employment opportunities on irrigated farms or higher wages on rainfed farms. Irrigation
enables farmers to obtain more output per unit of input which brings down the price of food on-
farm. In the macro-pathway, the gains in agricultural productivity through irrigation can stimulate
national and international markets, and can thus assist in improving economic growth and creating
second-generation positive externalities.
Thus, irrigation development has the potential to create windows of opportunities to improve
agricultural productivity. But then which upstream factors could create the enabling conditions for
such development? We draw on the opportunities offered to smallholder farmers in Kenya to tap
the potential provided by mobile payments and digital finance, namely through the M-Pesa
platform, to acquire small-scale irrigation equipment (Babcock, 2015). While the development and
use of ICTs have increased in developing countries, mobile payment has disruptively catalysed the
entrepreneurship, microfinance and services sectors. For example, Kickstart International, a non-


profit organisation, designed a mobile money product called 'Mobile Layaway', which enables farmers to make payments of any amount and any frequency through M-Pesa, to acquire an irrigation pump, the 'pata pump', which is human powered, either by pumping it manually or by pedalling it (Maree et al., 2013). This enables farmers to overcome the bottleneck of having to rely solely on rain-fed irrigation, which is becoming increasingly erratic due to climate change, to ensure crop growth and the production of quality produce at the farm-gate level. In this case analysis, we showcase how when stakeholders from various socio-economic spheres converge towards the successful deployment of infrastructure, human resource capabilities and social enterprise alliances (via market-supporting institutions and/or specialiszed intermediaries, etc.), it is possible to transform problematic situations into enabling environments for food production.

New trends in recent years have been changing the ways business is done in Africa. The rapid expansion of information and communication networks specifically, mobile technology - has provided tremendous new opportunities. Instead of playing catch-up, entrepreneurs in Africa are "hacking" existing infrastructure gaps through technology, connecting Africans to new goods and services. Such novel solutions to socio-economic problems are an outcome of the complex interactions of the social system that contribute varying patterns of skills, knowledge and history (Schwandt, Holliday \& Pandit et al., 2009). The contribution of youth should be mentioned here. In Africa, many young people are already involved in family farming. They undertake daily tasks and acquire knowledge and skills from their elderly family members and apply these techniques in their farming activities. They also bring agricultural technology and innovation into the family farm and are often involved in management activities that require their educational knowledge such as keeping accounts, communication with partners, NGOs etc. There is also another category of youth who are not directly involved in the field, but are developing ICT applications or offering ICT services which are useful to family farmers, especially women farmers (Rahman and \& Fong, 2016). Young agro-entrepreneurs bring their experiences with emerging technologies, accompanied by visions for a different agricultural value chain.

Harnessing and enabling the entrepreneurial skill and spirit of smallholder farmers, especially young people in the rural economy are therefore being mainstreamed at the forefront of current food security and economic empowerment agenda. Viewed from this perspective, a transdisciplinary approach to research and policy-making is required in order to improve the conceptual clarity of policymakers and development actors on the relative merits and potential future role, contribution, and impacts of alternative policies to enhance sustainability of food security interventions in developing countries, with special focus on agribusiness development. However, to achieve this development actors and decision makers need to adopt leadership styles and policymaking that are in conformity with dealing with complex and dynamic situations.

\section{How is agricultural innovation platforms governed?}

\subsection{Governance mechanisms that unleash capabilities}

How do we frame governance to bring innovation in in the smallholder business sector? What are the leadership implications for developmental practitioners? By drawing from complexity science, we explore the nature of interaction and adaptation and the way notions such as emergence, innovation, and fitness arise. When viewed from the lens of leadership, complexity science focuses on behaviours that enable organisational effectiveness, as opposed to determining or guiding effectiveness. This includes processes for managing dynamic systems and interconnectivity. One clear implication in dealing with complex problems is the need for increased emphasis on "governance" in development:

'In the face of intensification of societal complexity [...] we should see governance as the complex art of steering multiple agencies and institutions which are operationally autonomous from one another and structurally couple through [...] reciprocal interdependence. [...] Governance appears to have moved up the theoretical and 
practical agenda because complexity undermines the basis for hierarchical top-down control' (Jessop, 2003)

In developing countries, structures of governance already exist, although they are different to those in developed countries (Jones, 2011). These are rooted in day-to-day, ground level realities which are centred on various norms and values. These institutional arrangements have to be taken into consideration in the quest for establishing innovative practices in a sustainable manner and are what Roling (2016) referred to as the relational dynamics to crafting governance of IPs. Leadership in complex systems is about interactions and emergence. It is about events and how these shape future action (Lichtenstein et al., 2006). It is also about how human activity is organised into a system of choices and actions when organisations are considered to be complex adaptive systems where heterogeneous agents interact such that they and their activities evolve and change over time (Marion \&and Uhl-Bien, 20021).

\subsection{Harnessing meta-capabilities within Innovation Platforms}

How can adaptive capabilities can be harnessed by development actors within IPs to promote agribusiness development? Which institutional arrangements would enable farmers to make use of socio-technical improvements to improve their farm income sustainably in the developing world? What role should governance play under such complex systems? According to Plowman et al. (2007), leaders should be enablers - in that they disrupt existing patterns of behaviour, encourage, novelty and make sense of emerging events for others. Within this approach, leadership is considered as emerging from among multiple agents rather than as an individual or even a dyadic phenomenon. The instrumental impacts of leadership should be observed within the IP independent of individuals. This must be observed not only in the agents and what they do, but also in how the agents are connected into organisational capabilities.

Francis and \& van Huis (2016) noted that

"Some experts, development and innovation practitioners, and policymakers may have a problem in designating smallholder farmers as 'firms', although they are essentially entrepreneurs, operating a 'business' in a competitive environment." (p. 10)

Thus, rRecent research shows how farmers are being included in Innovation Platforms to create agricultural innovation systems that drive agricultural development. This is because Research \& Development and Science \& Technology are no longer considered as the main source of knowledge or drivers of socio-technological change. Even though this is regarded as a challenging concept to be applied to agricultural development, a burgeoning body of knowledge has emerged on the application of innovation systems to Agricultural Research and Development (Roling, 2016). As complex systems, organisations/firms/industries and therefore IPs, exist far from equilibrium where the ongoing interaction of system components leads to emergent and self-organising behaviour. Within Roling's (2016) cultural theory analysis of the IP literature, it is referred to as transformation from one set of situations to another. Pathways are created so that the agricultural sector can improve its sustainable transition. This is rendered possible when interactions with other areas of the economy can be strategically shaped.

How, then, should organisational capabilities be leveraged within IPs? Organisational capabilities were originally defined by Nelson and \& Winter (1982) in their book, An Evolutionary Theory of Economic Change, as roughly collections of routines, domain knowledge and decision capacity to get something done. A successful organiszation has many capabilities. The organisation's ability to build, extrapolate and recombine capabilities to move in new directions and to enable both operation and adaptation is referred to as its meta-capability; it is the capability to use other capabilities effectively. According to Hazy (2006), leadership must be observable as a meta-capability that connects and organises disparate agents into a complex adaptive system that acts as a unity in the environment. For example, running a smallholder venture effectively would be a capability. It requires successful interactions with various other actors on the agribusiness scene for input and 
marketing. Similarly, for international development experts to steer change successfully via Innovative Platforms to improve smallholder ventures requires harnessing meta-capabilities.

\subsection{How leadership leverage changes in complex systems?}

A conceptual version of the Leadership and Capabilities Model (LCM) of Hazy (2006) which has been adapted to demonstrate the harnessing of capabilities for agribusiness and rural enterprise development in developing African countries is shown in Figure 1. In the model, we consider the smallholder enterprises as firms. Agribusiness and rural enterprise is considered as a system of human interactions within the complex adaptive systems viewpoint. These human interactions consist of two major aspects. First, autonomous agents must interact in some form of coordinated action. In an IP, this would include farmers, the private sector from diverse socio-economic spheres, financial institutions, international development practitioners, academicians, local development practitioners, government civil servants, social enterprise, NGOs and other non-state actors. Second, these agents and their resource, tasks, and knowledge must change over time; and to the extent that they improve the systems, that is the IP's, ability to make use of the environment. The changes must be differentially selected and retained by the system in response to changes in the environment. This refers to the selection of pathways to adapt and innovate within the IPs. For example, in Benin, a women's cooperative eventually extended their activities from the traditional cotton plantation to include a neem-based natural pesticide enterprise within the IP to improve their yield and profitability (Jiggins et al., 2016). This was an activity that was not envisioned in the initial phase of the innovation pathway and institutional arrangements had to be re-configured to accommodate and enable this change.

In the LCM (Hazy, 2006), leadership is central to this process of change, variation, selection, and retention. Leadership activities taken together constitute the system level mechanism that exerts leverage on these system processes in five ways. These are the five value-creating levers, shown as $\mathrm{A}$, $\mathrm{B}, \mathrm{C}, \mathrm{D}$ and $\mathrm{E}$, available to the leadership meta-capability to regulate performance and adaption in an effort to sustain the arrangements agreed upon within the IP.

Leadership involves actions among agents that identify or espouse a cooperation strategy, shown as A, in Figure 1. The aim is to create more efficient operations e.g. by recognising the possibilities for creating linkages amongst agents and institutions in IPs. Ultimately, more slack resources are generated for the system's use. Resource slack, in the business and management literature, is the level of availability of a resource (Dolmans et al., 2015). Within IPs, slack resources can be goods/capital/services, profits and knowledge gained throughout the transformation process.

Having highlighted the potential of the IP for transformation, leadership activities should catalyse conditions where other agents choose to participate in the program via strategically focused partnerships (Lever B). This increases or improves the current capabilities and may include investment in technology, human and intellectual capital, and other assets that increase capacity and effectiveness at both appropriating known resources and processing them for the IP's benefit. Ultimately, there is an increase in the level of slack resources available to the system.

How can the level of slack resources be increased to leverage smallholder farming and social entrepreneurship? It is to be recalled that, from a systemic viewpoint, smallholder ventures and social entrepreneurship fit in a self-reinforcing feedback loop which can then have spill-over effects into the wider socio-economic spheres. In much of the developing world, smallholder farmers and for many small and micro- enterprises, there is the major issue of sustainable access to finance and markets, and for potential customers, there are perennial complaints about quality control, packaging and labelling, etc. In an extensive study, Tenywa et al. (2011) explained the importance of Enabling Rural Innovation (ERI) systems whereby capacity building is harnessed at different levels to provide smallholders and entrepreneurs access to relevant and meaningful training. Rahman and \& Fong (2016) relate how inductions training via social entrepreneurship ventures by youth groups 
that provide agricultural market information to women farmers also contribute to leverage the adoption of innovation practices to boost farming. Such capacity building systems could occur, at the third point, shown as " $\mathrm{C}$ " in Figure 1. Leadership can bias the flow of information within and across the IP's boundary to encourage learning, sharing of knowledge, and experimentation by identifying stakeholder groups and the specific potential contribution within the IP. This has the dual effect of increasing the possibilities within and attracting possibilities from outside of the IP. Astute governance mechanisms organise choices and actions in actors to navigate complexity so that lever $\mathrm{D}$, leadership can bias the flow of slack resources toward nurturing possibilities identified in the learning and experimentation process and toward building new capabilities that may create previously unknown opportunities for appropriating resources from the environment. This is a critical component of adaptation that feeds itself from the concept feedback perspective.

The form, nature and time taken by agricultural formation process depends on both the conceptual and local context, quality of facilitation, socio-economic, culture, biophysical, political environment in which a common challenge and/or opportunity is identified and on the capacity of stakeholders to comprehend the Innovation Systems Approach. An example of governance mechanism that can have far-reaching influence here would be wide-scale anti-corruption sensitisation campaigns supported by organisations that have research and development brokerage roles, in order to create impact (Dasgupta \&and Roy, 2011).

Leadership is uniquely positioned to take a system perspective and balance the points of tension and risks inherent in the other points of leverage described. These are achieved via distributed leadership mechanisms that respond to system-level effects to strategically manage the storage, distribution, and use of slack resources for the long- and short-term benefit of the innovation system and its stakeholders. This influence is shown as lever E (Figure 1).

Together, these five leverage points enable the leadership meta-capability to guide the IP as an entity, that is able to appropriate resources from the environment, support its member agents and other coevolving entities (such as customers and suppliers). It has to simultaneously adapt its internal capabilities to likewise co-evolve with the environment and sustain the system as the environment changes over time.

\subsection{Research implications for understanding leadership style in Innovation Platforms}

How can we improve the knowledge of leadership styles within social-agribusiness systems? There is no universal solution to handle complexity in smallholder agribusiness innovation systems in African countries. Distilling bottlenecks revolves around context-specificity within and outside the smallholder domains. This is an understudied phenomenon (Roling, 2016), since IPs have only recently been established (last 10 years), to gauge a comprehensive impact. More research is required to understand how to craft responsive leadership styles that need to be adopted by governmental policy-makers, international development brokers, local development practitioners and small-holder collectives. In fact, the leadership scholarship need to adopt Africa as a research context, to demonstrate how these understudied phenomena influence strategic focus in the smallholder and rural enterprise development sector since decisions taken have to be adaptive enough to deal with local pervasive problems as well as concatenated issues due to the post-globalisation era. 


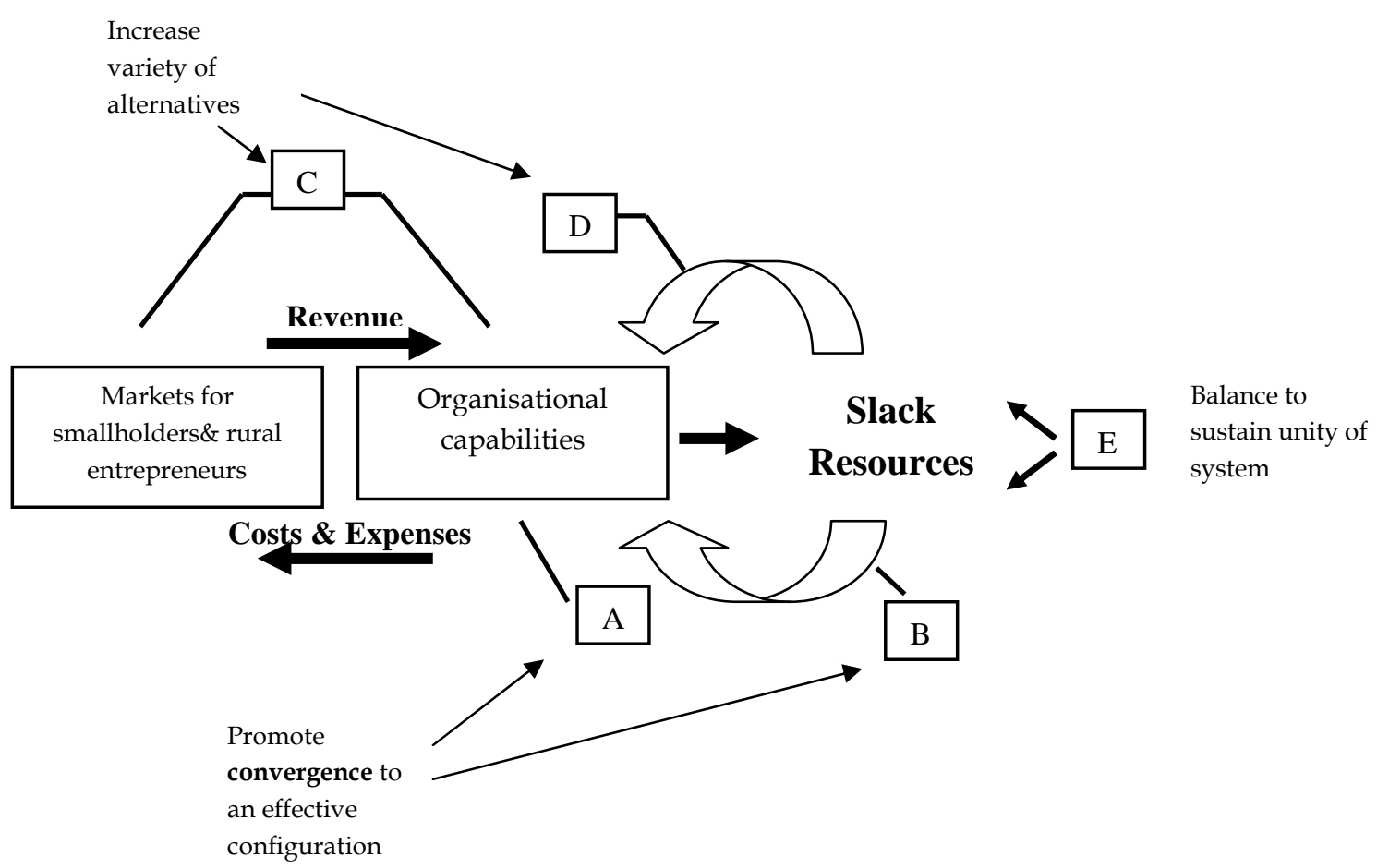

Figure 1. Complex socio-technical systems survive by building and capabilities that appropriate resources from the environment and store excess as slack resources. Leadership operates at five points of leverage, indicated by A, B, C, $\mathrm{D}$ and $\mathrm{E}$. A and $\mathrm{B}$, support the convergence of the system towards an attractor that represents an effective configuration. $\mathrm{C}$ and $\mathrm{D}$, increase the variety of possibilities within the system. The final leverage point, E, balances tension within the system and performs activities that maintain the sense of unity and purpose for the system and its members as these internal tensions ebb and flow.

(Adapted from Hazy, 2006)

\subsection{Research implications for understanding leadership style in Innovation Platforms}

How can we improve the knowledge of leadership styles within social-agribusiness systems? There is no universal solution to handle complexity in smallholder agribusiness innovation systems in African countries. Distilling bottlenecks revolves around context-specificity within and outside the smallholder domains. This is an understudied phenomenon (Roling, 2016), since IPs have only recently been established (last 10 years), to gauge a comprehensive impact. More research is required to understand how to craft responsive leadership styles that need to be adopted by governmental policy-makers, international development brokers, local development practitioners and small-holder collectives. In fact, the leadership scholarship need to adopt Africa as a research context, to demonstrate how these understudied phenomena influence strategic focus in the smallholder and rural enterprise development sector since decisions taken have to be adaptive enough to deal with local pervasive problems as well as concatenated issues due to the post-globalisation era.

Hazy (2006) based the LCM on an evolutionary economics perspective and the resource based view (RBV) of the firm to coin the term 'Performance rent' as a means to measure the value created by the leadership meta-capability of the system over time. Under this perspective, sustainable competitive advantage is derived from unique and sustained access to resources, including knowledge, and the ability to exploit that access to the continued benefit of the organisation. This economic benefit accrues in the form of economic rents, that is, excess returns derived from control of scarce resources. This also includes proprietary knowledge. Since the level of economic rent supports sustainability and is determined by the firm's performance, it is a measure of the organisation's fitness for a given configuration of its capabilities. Thus, in the context of unleashing smallholder ventures through social entrepreneurship, the fitness of an IP can be 
measured at different levels by analysing its 'performance landscape'. This refers to all the levels of performance within a complex system by virtue of its many internal configurations and their interactions (Siggelkow, 2002). Performance rent can thus be considered to measure the value created by the leadership meta-capability of the system over time. It is thus an operating metaphor for leadership that can be applied to the evaluation of governance effectiveness in IPs.

Given that a of body research has already been started in the smallholder innovation systems, we believe that special emphasis should be placed on the application of Individual Depth Interviews of well qualified respondents who are at the fore-front in engaging with complexity at different levels within the smallholder and agribusiness community in order to extract experiential information that can be analysed from the leadership and complexity science perspective. The aim should be the continuous discernment of knowledge, to the benefit of smallholders, social entrepreneurs and to gain buy in from other private actors from the wider socio-economic sector that tallies somehow along the lines of the theme for this year's World Economic Forum in Davos which is responsive leadership (Giles, 2017). A responsive socio-technical system can adapt to change and is resilient in the face of adversity for it encourages different types of innovation and transformation, building on local knowledge and initiatives to embed technological innovations. EIn order to engineering this style of "adaptive governance" will require designing laws, incentives, regulations or safeguards that have the same self-organising principles that define the complex systems they are meant to deal with.

\section{Conclusion}

This paper is intended to critically inform the role that social entrepreneurship can play in unleashing sustainable ventures at the smallholder level in developing African countries. We draw essentially on the burgeoning literature on how innovation platforms have been recently applied within agricultural innovation systems and an example of the waysuccessful trans-sectoral collaboration through mobile payments are already leveraging change to suggest that strategic institutional entrepreneurship should be embedded and facilitated. Astute steering of leadership capabilities is key to mobilising the multitude of stakeholders to create variety of pathways to innovate, establish linkages and distil institutional complexity. The key limitation of this paper is that it is conceptual in nature. However, recent evidence shows that there is scope for further research to improve the practical understanding of how the smallholder and immediate communities can tap opportunities to innovate. If governments and institutions embrace the science of complexity in policy decisions for mainstreaming social agro-entrepreneurship within agricultural IPs, economic actors, including smallholder farmers and citizens can anticipate a novel kind of policy making that would dynamically and rapidly evolve and change in context.

\section{References}

Alliance for a Green Revolution in Africa. (2014) Climate change and small-holder agriculture in subSaharan Africa. Africa Agriculture Status Report. Nairobi, Kenya: Alliance for a Green Revolution in Africa.

Babcock, L. (2015) Mobile Payments: How Digital Finance is Transforming Agriculture. Wageningen, Netherlands: Technical Centre for Agricultural and Rural Co-operation.

Banson, K.E., Nguyen, N.C., Bosch, O.J.H., Nguyen, T.V. (2015) A Systems Thinking Approach to Address the Complexity of Agribusiness for Sustainable Development in Africa: A Case Study in Ghana. Systems Research and Behavioral Science 32(6): 672-688.

Babu, S.C., Manvatkar, R., Kolavalli, S. (2015) Strengthening Capacity for Agribusiness Development and Management in Sub-Saharan Africa. Africa Journal of Management DOI:

10.1080/23322373.2015.1112714

Bolo, M. (2016) Innovation Systems and Capability Building among Smallholder Farmers: Lessons and Insights from Kenya's Flower Farmers. In: Francis, J., Mytelka, L., van Huis, A., Röling, N. (Eds.) Innovation Systems: Towards Effective Strategies in Support of Smallholder Farmers. Technical 
Centre for Agricultural and Rural Cooperation (CTA) and Wageningen University and Research (WUR) Convergence of Sciences - Strengthening Innovation Systems (CoS-SIS) programme, Wageningen.

Burney, J.A., Naylor, R.L., Poste, S. L. (2013) The case for distributed irrigation as a development priority in sub-Saharan Africa. Proceedings of the National Academy of Sciences 110(31): 1251312517.

Chauvin, N.D., Mulangu, F., Porto, G. (2012) Food production and consumption trends in subSaharan Africa: Prospects for the transformation of the agricultural sector. New York, USA: UNDP Regional Bureau for Africa.

Dasgupta, S. \& Roy, I. (2011) Good Agricultural Governance: A resource guide focused on smallholder crop production. RAP Publication 2011/18. Bangkok, Thailand: Food and Agriculture Organisation of the United Nations.

Diao, X., Headey, D., Johnson, M. (2008) Towards a green revolution in Africa: what would it achieve, and what would it require? Agricultural Economics 39(1): 539-550.

Dolmans, S.A.M., Reymen, I.M.M.J., van Burg, E., Romme, A.G.L. (2014) Dynamics of resource slack and constraints: Resource positions in action. Organization Studies 35(4): 511-549.

Faure's, J.M. \& Santini, G. (2008) Water and the Rural Poor: Interventions for Improving Livelihoods in Sub-Saharan Africa. Rome, Italy: Food and Agricultural Organisation of the United Nations.

Francis, J.A. (2016) Innovation systems, agricultural development and economic empowerment: Lessons from CTA's agricultural science technology and innovation system capacity building programme -implications for policy. In: Francis, J., Mytelka, L., van Huis, A., Röling, N. (Eds.) Innovation Systems: Towards Effective Strategies in Support of Smallholder Farmers. Technical Centre for Agricultural and Rural Cooperation (CTA) and Wageningen University and Research (WUR) Convergence of Sciences - Strengthening Innovation Systems (CoS-SIS) programme, Wageningen.

Francis, J.A. \& Van Huis, A. (2016) Introduction. Why Focus on Innovation Systems: Implications for Research and Policy? In: Francis, J., Mytelka, L., van Huis, A., Röling, N. (Eds.) Innovation Systems: Towards Effective Strategies in Support of Smallholder Farmers. Technical Centre for Agricultural and Rural Cooperation (CTA) and Wageningen University and Research (WUR) Convergence of Sciences - Strengthening Innovation Systems (CoS-SIS) programme, Wageningen.

Fuglie, K.O. and Nicholas E. R. (2013) Resources, Policies, and Agricultural Productivity in Sub-Saharan Africa. Report ERR-145. USA: Department of Agriculture, Economic Research Service.

Fuss, S., Havlík, P., Szolgayová, J., Schmid, E., Reuter, W.H., Khabarov, N., Obersteiner, M., Ermoliev, Y., Ermolieva, T. and Kraxner, F. (2015) Global food security and adaptation under crop yield volatility. Technological Forecasting and Social Change 98: 223-233.

Giles, C. (2017) Davos elites need to heed the wrath of the 'left behind'. Financial Times. 17 Jan 2017.

Godfray, H.C.J., Beddington, J. R., Crute, I.R., Haddad, L., Lawrence, D., Muir, J.F., Pretty, J., Robinson, S., Toulmin, C. (2010) Food security: The challenge of feeding 9 billion people. Science 327: 811-818.

Graeub, B.E., Chappell, M.J., Wittman, H., Ledermann, S., Kerr, R.B., Gemmill-Herren, B. (2016) The state of family farms in the world. World Development 87: 1-15.

Hazy, J.K. (2006) Measuring leadership effectiveness in complex socio-technical systems. EmergenceMahwah-Lawrence Erlbaum 8(3): 58.

High Level Panel of Expert (HLPE). (2013) Investing in smallholder agriculture for food security. Rome, Italy: High Level Panel of Experts on Food Security and Nutrition of the Committee on World Food Security.

Hussain, I. \& Hanjra. M.A. (2004) Irrigation and poverty alleviation: review of the empirical evidence. Irrigation and Drainage 53 (1):1-15. 
Ison, R. (2010) Systems practice: how to act in a climate change world. London: Springer Science \& Business Media.

Ison, R., Blackmore, C., Iaquinto, B.L. (2013) Towards systemic and adaptive governance: exploring the revealing and concealing aspects of contemporary social-learning metaphors. Ecological Economics 87: 34-42.

Jessop, B. (2003) Governance and meta-governance: on reflexivity, requisite variety and requisite irony. In: Bang, H.P. (Ed.) Governance as social and political communication.UK: Manchester University Press, pp.101-116.

Jiggins, J., Essegbey, G., Klerk, L., van Paassen, A., Pyburn, R., Tossou, R. (2016) The uses of research: Action researching in and across nine agro-enterprise domains. The experience of the Convergence of Sciences - Strengthening Innovation Systems programmes in Benin, Ghana and Mali. In: Francis, J., Mytelka, L., van Huis, A., Röling, N. (Eds.) Innovation Systems: Towards Effective Strategies in Support of Smallholder Farmers. Wageningen: Technical Centre for Agricultural and Rural Cooperation (CTA) and Wageningen University and Research (WUR) Convergence of Sciences - Strengthening Innovation Systems (CoS-SIS) programme.

Jones, S. (2011) Participation as citizenship or payment? A case study of rural drinking water governance in Mali. Water alternatives 4(1): 54.

Khanna, T. and Palepu, K. (2013) Winning in emerging markets: A road map for strategy and execution. Massachusetts, USA: Harvard Business Press.

Lichtenstein, B.B., Uhl-Bien, M., Marion, R., Seers, A., Orton, J.D., Schreiber, C. (2006) Complexity leadership theory: An interactive perspective on leading in complex adaptive systems. Emergence: Complexity and Organization 8(4): 2-12.

Marion, R. and Uhl-Bien, M. (2002) Leadership in complex organizations. The Leadership Quarterly 12(4): 389-418.

Marree, J., Piontak, R., Omwansa, T., Shinyokwa, I., Njenga, K. (2013) Developmental uses of mobile phones in Kenya and Uganda. Capturing the Gains Programme. Working Paper 35. UK: University of Manchester, School of Environment and Development.

Masetti, B. L. (2009) The social entrepreneurship matrix as a "Tipping Point" for economic change. In: Goldstein, J.A., Hazy, J.K., Silberstang, J. (Eds.) Complexity science and social entrepreneurshipAdding social value through systems thinking: Exploring Organizational Complexity. Volume 3. Arizona, United States: ISCE Publishing.

Moyo, J. M., Bah, El-H.M., Verdier-Chouhane, A. (2015) Transforming Africa's agriculture to improve competitiveness. The Africa Competitiveness Report. Ivory Coast: African Development Bank.

Mytelka, L.K. (2016) Innovation Systems approaches in a time of transition. In: Francis, J., Mytelka, L., van Huis, A., Röling, N. (Eds.) Innovation Systems: Towards Effective Strategies in Support of Smallholder Farmers. Wageningen: Technical Centre for Agricultural and Rural Cooperation (CTA) and Wageningen University and Research (WUR) Convergence of Sciences Strengthening Innovation Systems (CoS-SIS) programme.

Nelson, R.R. \& Winter, S.G., (1982) The Schumpeterian trade-off revisited. The American Economic Review 72(1):114-132.

Page, J. (2016) Industry in Tanzania: Performance, prospects, and public policy. 2016/5. Helsinki: UNUWIDER.

Peredo, A.M. \& McLean, M. (2006) Social entrepreneurship: a critical geography of the concept. Journal of World Business 41(1): 56-65.

Pingali, P.L. (2012) Green revolution: impacts, limits, and the path ahead. Proceedings of the National Academy of Sciences 109(31): 12302-12308.

Plowman, D.A., Solansky, S., Beck, T.E., Baker, L., Kulkarni, M., Travis, D.V. (2007) The role of leadership in emergent, self-organization. The Leadership Quarterly 18(4): 341-356. 
Rahman, R. \& Fong, J. (2016) Innovate for agriculture - Young ICT entrepreneurs overcoming challenges and transforming agriculture. Wageningen, Netherlands: Technical Centre for Agricultural and Rural Cooperation.

Raikundala, S. (2016) Balancing entrepreneurial values with social impact. Technical Centre for Agricultural and Rural Cooperation ACP/EU Bulletin ICT Update 83: 10-11.

Roling, N. (2016) Innovation systems, and beyond: Using cultural theory to understand approaches to smallholder development in Sub-Saharan Africa. In: Francis, J., Mytelka, L., van Huis, A., Röling. (Eds.) Innovation Systems: Towards Effective Strategies in Support of Smallholder Farmers. Wageningen: Technical Centre for Agricultural and Rural Cooperation (CTA) and Wageningen University and Research (WUR) Convergence of Sciences - Strengthening Innovation Systems (CoS-SIS) programme.

Sanginga, N. (2015) Youth in Agribusiness within an agricultural transformation agenda. Background Paper. Feeding Africa: An Action Plan for African Agricultural Transformation. 21-23 October 2015. Abdou Diouf International Conference Centre, Dakar, Senegal.

Schultz, R. (2009) Social business: Designing the possibility space for action. In: Goldstein, J.A., Hazy, J.K., Silberstang, J. (Eds.) Complexity science and social entrepreneurship-Adding social value through systems thinking: Exploring Organizational Complexity Volume 3. Arizona, United States: ISCE Publishing.

Schwandt, D.R., Holliday, S., Pandit, G. (2009) The complexity of social entrepreneurship systems. In: Goldstein, J.A., Hazy, J.K., Silberstang, J. (Eds.) Complexity science and social entrepreneurshipAdding social value through systems thinking: Exploring Organizational Complexity Volume 3. Arizona, United States: ISCE Publishing.

Sheahan, M. \& Barrett, C.B. (2014) Understanding the agricultural input landscape in sub-Saharan Africa: Recent plot, household, and community-level evidence. Policy Research working paper No. WPS 7014. Washington, DC: World Bank Group.

Siggelkow, N. (2002) Evolution toward fit. Administrative Science Quarterly 47(1): 125-159.

Slimane, M.B., Huchet-Bourdon, M., Zitouna, H. (2016) The role of sectoral FDI in promoting agricultural production and improving food security. International Economics 145: 50-65.

Swaminathan, M.S. (2010) Achieving food security in times of crisis. New Biotechnology 27(5): 453-460.

Triomphe, B., Floquet, A., Kamau, G., Letty, B., Vodouhé, D.S., N'gan'ga, T., Stevens, J., van den Berg, J., Selemna, N., Bridier, B., Crane, T., Almekinders, C., Waters- Bayer, A., Oudwater, N. and Hocdé, H. (2013) What does an inventory of recent innovation experiences tell us about agricultural innovation in Africa? Journal of Agricultural Education and Extension 19(3):311-324.

Tittonell, P., Muriuki, A.W., Shepherd, K.D., Mugendi, D., Kaizzi, K.C., Okeyo, J., Verchot, L., Coe, R., Vanlauwe, B. (2010) The diversity of rural livelihoods and their influence on soil fertility in agricultural systems of East Africa - A typology of smallholder farms. Agricultural Systems 103: 83-97.

United Nations Development Programme (UNEP). (2012) Africa human development report 2012: Towards a food secure future. Available at

http://www.undp.org/content/undp/en/home/librarypage/hdr/africa-human-developmentreport-2012/. Accessed 29 January 2017.

Van Paassen, A., Klerkx, L., Adu-Acheampong, R., Adjei-Nsiah, S., Zannoue, E. (2014) Agricultural innovation platforms in West Africa: How does strategic institutional entrepreneurship unfold in different value chain contexts? Outlook on Agriculture 43(3):193-200.

World Bank. (2008) World Development Report 2007. Washington, DC: The World Bank.

World Bank. (2013) Growing Africa: Unlocking the potential of agribusiness. Washington, DC: The World Bank.

Tenywa, M.M., Rao, K.P.C., Tukahirwa, J. B., Buruchara, R., Adekunle, A. A., Mugabe, J., Wanjiku, C., Metabasin, S., Fungo, B., Kashaija, N.I., M., Pali, P., Mapatano, S., Ngaboyisonga, C., Farrow, A., Njoku, J. and Abenakis, A. (2011) Agricultural Innovation Platform as a tool for 
development oriented research: Lessons and challenges in the formation and operationalization. Learning Publics Journal of Agriculture and Environmental Studies 2(1): 117146. 